\title{
Effects of the Horse Riding Simulator and Ball Exercises on Balance of the Elderly
}

\author{
SeongGil Kim, PT, MS ${ }^{1)}$, Goon-chang Yuk, PT, PhD ${ }^{2)}$, Hwangbo Gak, PT, $\mathrm{PhD}^{3)^{*}}$ \\ 1) Department of Rehabilitation Science, Graduate School, Daegu University, Republic of Korea \\ 2) Department of Physical Therapy, Yeungnam University Hospital, Republic of Korea \\ 3) Department of Physical Therapy, College of Rehabilitation Science, Daegu University: 15 Jilyang, \\ Gyeongsan-si, Kyeongbuk 712-714, Republic of Korea
}

\begin{abstract}
Purpose] The aim of this study was to examine the effects of horse riding exercise using a horse riding simulator (HRS) and a ball on static and dynamic balance of elderly people. [Methods] Thirty-two elderly people hospitalized in geriatric hospitals were randomly assigned to the HRS exercise group or the ball exercise groups, and they performed exercise for eight weeks. [Results] The length of postural sway during quite standing with and without eyes closed significantly decreased in both groups after the exercises and there was no significant difference between both groups in the Romberg test. In the functional reach test (FRT), there were significant increases in distance in both groups after the exercises, and the distance of the HRS exercise group was significantly greater than that of the ball exercise group. In the Timed Up \& Go test (TUG) and Timed 10-meter walk test (10MWT), the time significantly decreased in both groups, and there was a more significant decrease in the HRS exercise group than in the ball exercise group. [Conclusion] The results of this study indicate that HRS and ball exercises may improve the balance and gait ability of elderly people hospitalized in nursing homes or geriatric hospitals.

Key words: Elderly, Balance, Hippotherapy
\end{abstract}

(This article was submitted May 9, 2013, and was accepted Jun. 7, 2013)

\section{INTRODUCTION}

Although the development of science and medicine has resulted in longer human lifespans decreased balance control ability due to aging may degrade elderly people's quality of life. Many aged people receive injuries such as fracture or brain damage, or even die in falls, and the risk of falls increases even for the uninjured because of the functional loss that occurrs secondary to restricted activities, due to fear or concern about another fall ${ }^{1)}$. Continuous exercise and environmental improvement are effective at increasing stability and reducing the risk of fall for elderly people ${ }^{2,3)}$. Diverse tools and programs are utilized in order to induce interest and motivate elderly people whose will to exercise has been degraded because of low activity levels and quality of life ${ }^{4,5)}$. In particular, activity levels of elderly people residing in hospitals or nursing homes, where they mostly stay indoors, are lower than those of elderly people who independently conduct daily living activities, and therefore specific exercise programs are necessary for such persons ${ }^{4}$. Research on the effects of fall prevention programs practiced by hospitals have reported that fall

*Corresponding author. Hwangbo Gak (e-mail: hbgak@ daegu.ac.kr)

(C2013 The Society of Physical Therapy Science

This is an open-access article distributed under the terms of the Creative Commons Attribution Non-Commercial No Derivatives (by-ncnd) License $<$ http://creativecommons.org/licenses/by-nc-nd/3.0/>. prevention programs in acute hospitals are effective at reducing falls ${ }^{6}$, and targeted multifaceted interventions are helpful for decreasing fall incidents in hospitals ${ }^{7}$. On the other hands, fall prevention programs for patients who stay in hospital for a short period have proven ineffective ${ }^{8}$.

Hippotherapy is drawing attention as a new treatment technique for improving balance and gait ability ${ }^{9-11)}$. Movements of horse walking and the rhythms on horseback are similar to those of normal human gait. Feeling the rhythms on horseback gives comfort and pleasure and may be helpful for emotional stability. Therefore horse riding is employed in rehabilitation as well as in the fields of sports or recreation. Hippotherapy is known to be effective for improvement of subjects' three-dimensional movements using the horse as a medium, as well as inducing responses to the horse's movements, adjusting abnormal muscle tension, improving movement patterns, strengthening muscles, adjusting balance of the trunk, and enhancing gait ${ }^{12,13)}$.

Hippotherapy has been utilized to treat cerebral palsy ${ }^{13)}$, multiple sclerosis ${ }^{14)}$, spinal cord injury ${ }^{15)}$, stroke ${ }^{10)}$, and intellectual disabilities ${ }^{12}$. It is difficult to secure space for the therapy, and maintenance costs of horses and facilities are expensive. In addition, there is the risk of falls ${ }^{16)}$. Therefore, horse riding equipment or tools imitating a horse's movements that may be utilized indoors have been recently developed ${ }^{17,18)}$. A horse riding simulator or tools for hippotherapy could be employed for functional improvement and fall prevention of elderly people hospitalized in nursing homes or geriatric hospital, but relevant studies are insufficient. Therefore, this study examined the effects of horse 
Table 1. General characteristics of subjects

\begin{tabular}{lcc}
\hline & HRS exercise group & Ball exercise group \\
\hline Gender (M/F) & $5 / 10$ & $6 / 9$ \\
Age (year) & $78.4 \pm 6.2$ & $78.5 \pm 6.6$ \\
Height $(\mathrm{cm})$ & $157.7 \pm 5.5$ & $157.6 \pm 5.5$ \\
Weight $(\mathrm{kg})$ & $56.6 \pm 8.6$ & $56.1 \pm 8.0$ \\
\hline
\end{tabular}

Mean \pm SD, HRS: horse riding simulator

riding exercises on the HRS and a ball on static and dynamic balance of elderly people.

\section{SUBJECTS AND METHODS}

In this study, thirty-two elderly people hospitalized in geriatric hospitals were randomly assigned to the HRS exercise group or the ball exercise group and they performed exercise for eight weeks (Table 1). The criteria for the selection of the subjects were as follows: 65 years of age or older; no experience of a fall in the last one year; ability to walk more than $10 \mathrm{~m}$ without the help of gait aiding tools or other persons; no disease that might have affected the performance of exercise programs; and a score of 24 or higher score on the Korean version of the mini-mental state examination (MMSE-K). The exclusion criteria were as follows: visual or auditory deficit or problems with the vestibular system; and inability to understand the content of the experiment.Information about this study was provided to all the subjects and they submitted their written consent to participation in this study. They were permitted to receive ordinary physical therapy during the study period. Ethical approval was obtained from the research ethics boards of Daegu University and local hospital.

Both the HRS exercise group and the ball exercise group performed horse riding exercise five times per week, 20 minutes each time.

The HRS (Honjin, Korea) was developed for indoor hippotherapy, and it imitates the three-dimensional movements (forward and backward, left and right, and up and down) of a live horse. Images of horse riding are displayed at the front for visual reality effects. The HRS group did warmup exercise for 5 minutes prior to the horse riding exercise and a physical therapist continuously observed them during the 15-minute horse riding exercise for their safety. While the HRS was moving, the subjects maintained balance, and the speed of HRS was adjusted to be physical capabilities of each subject. The ball exercise was conducted in a similar manner to horse riding, with the subject riding on the ball. The exercise program consisted of pelvic tilt on the ball (forward and backward, side to side) and bounce on the ball (up and down). A research assistant demonstrated how to exercise on the ball, and after 5 minutes of warm-up exercise, the subjects performed the exercise for 15 minutes. The ball used in the study was the Professional Exercise Ball (Thera-Band, USA) and the diameter of the ball was 55 to $65 \mathrm{~cm}$, so that the subject's feet were comfortably placed on the ground when sitting on the ball.

The Romberg test was used to assess static balance.
Table 2. Results of the Romberg test (Eyes open/closed) for static balance

\begin{tabular}{llcc}
\hline Variable & Group & Pre & Post \\
\hline EO lengh & HRS exercise & $48.9 \pm 11.6$ & $45.2 \pm 12.7^{*}$ \\
$(\mathrm{~cm})$ & Ball exercise & $51.4 \pm 15.3$ & $38.4 \pm 10.8^{*}$ \\
EC lengh & HRS exercise & $64.2 \pm 21.0$ & $46.3 \pm 15.6^{*}$ \\
$(\mathrm{~cm})$ & Ball exercise & $62.3 \pm 20.3$ & $41.9 \pm 11.7^{*}$ \\
\hline
\end{tabular}

${ }^{*} \mathrm{p}<0.05$ Mean \pm SD, EO: eyes open, EC: eyes closed, HRS: horse riding simulator

Subjects stood on the platform of the Bioresque (RM Ingenierie, France) place their feet shoulder width apart with their eyes open for 1 minute, and then closed their eyes for another minute. The length of the center of pressure sway was measured.FRT was used to assess dynamic balance in standing. The subjects stood barefoot, placed their feet shoulder width apart, and held both arms parallel to the ground with the palms facing down. The subjects extended both arms to the maximum, then stretched forward as far as possible with their arms parallel to the ground and the distance moved was measured. In order to measure dynamic balance and agility, the TUG test was used ${ }^{19)}$. The subject sat in an armchair. At the start of the test, they stood up and walked 3 meters, then walked back to and sat in the armchair. Individuals walked $10 \mathrm{~m}$ without assistance and the time taken to walk the intermediate 6 meters was measured to eliminate the effects of acceleration and deceleration. Each measurement was made three times and the best record was used.

The paired t-test was used in order to examine differencess between pre- and post-exercise in both groups and the independent sample t-test was conducted for comparison between the HRS exercise and ball exercise groups. The PASW 18.0 program (SPSS Inc., Chicago, IL, USA) was used for data analysis. The results were accepted as statistically significant for values of $\mathrm{p}<0.05$.

\section{RESULTS}

The pre- and post-exercise results are described in Tables 2 and 3. In the Romberg test, the length of postural sway with eyes open significantly decreased in both groups after exercise $(p<0.05)$, but there was no significant difference between the HRS exercise group and the ball exercise group $(p>0.05)$. The length of postural sway with eyes closed significantly decreased in both groups after exercise $(p<0.05)$, but there was no significant difference between the HRS exercise group and the ball exercise group $(\mathrm{p}>0.05)$ (Table 2).

In FRT, there was a significant increase in FRT distances in both the HRS exercise group and the ball exercise group $(\mathrm{p}<0.05)$, and the distance of the HRS exercise group was significantly greater than that of the ball exercise group after the exercise $(p<0.05)$. In TUG and 10MWT, the times significantly decreased in both groups $(\mathrm{p}<0.05)$, and the HRS exercise groups time decreased significantly more than that of the ball exercise group $(\mathrm{p}<0.05)$ (Table 3$)$. 
Table 3. Results of FRT distance, TUG and 10MWT, measures of dynamic balance and gait

\begin{tabular}{llcc}
\hline Variable & Group & Pre & Post \\
\hline \multirow{2}{*}{ FRT $(\mathrm{cm})$} & HRS exercise & $14.8 \pm 5.0$ & $28.8 \pm 5.5^{\mathrm{ab}}$ \\
& Ball exercise & $15.3 \pm 5.0$ & $22.2 \pm 4.9^{\mathrm{ab}}$ \\
\multirow{2}{*}{ TUG $(\mathrm{sec})$} & HRS exercise & $18.9 \pm 8.2$ & $12.8 \pm 4.3^{\mathrm{ab}}$ \\
& Ball exercise & $20.0 \pm 7.1$ & $16.5 \pm 4.5^{\mathrm{ab}}$ \\
\multirow{3}{*}{ 10MWT $(\mathrm{sec})$} & HRS exercise & $13.5 \pm 6.9$ & $7.2 \pm 2.2^{\mathrm{ab}}$ \\
& Ball exercise & $12.4 \pm 5.8$ & $9.7 \pm 2.2^{\mathrm{ab}}$ \\
\hline
\end{tabular}

FRT: Functional reach test; TUG: Timed up and go test; 10MWT: Timed 10-meter walk test; HRS: horse riding simulator. ${ }^{\text {a }}$, significant difference between pre and post; ${ }^{b}$, significant difference between the HRS and Ball groups, post-exercise.

\section{DISCUSSION}

Among diverse prevention methods for elderly people's falls, hippotherapymay be a successful intervention strategy providing both safety and pleasure. This study examined the effects of horse riding exercise on static and dynamic balance, and gait ability of elderly people, and we verified that horse riding exercise using the HRS or the ball significantly improved their balance and gait.

Elderly people's postural sway is larger than that of young people ${ }^{20}$, and the range of postural sway of those who have several experiences of fall is larger than that of those who do not, and their balance responses are delayed. Therefore, they have difficulty in efficient postural adjustment and a higher risk of fall ${ }^{1,21)}$. In this study, the length of postural sway in standing with the eyes open and closed significantly decreased after 8 weeks of exercise. However, Araujo observed that the static balance of the elderly who live at home didn't show significant difference after horse riding exercise ${ }^{9)}$. The differences between the findings of this study and previous reports may be due to the health status of the subjects. Those who participated in Araujo's study were physically healthy and able to do ordinary activities at home, whereas those who participated in this study were hospitalized in geriatric hospitals and did relatively fewer activities. Kim reported that the elderly living at home had significantly higher scores of fitness and activities of daily living than those living in institutions ${ }^{22}$. It is known that appropriate ankle and hip postural strategies are necessary for maintaining dynamic balance while standing, and an increase in FRT distance indicates improvement of dynamic balance ability in the standing position. In this study, FRT distance significantly increased in both the HRS and the ball exercise groups. A similar increase in FRT distance was found by Mitani, whose study reported posture and movement of the elderly improved after 12 weeks of HRS exercise ${ }^{17)}$.

In this study, TUG performance time decreased and gait speed increased after both the HRS exercise and the ball exercise. The study by Mitani used a device similar to the HRS in our present study, and the study of Araujo. Which conducted equine-assisted therapy, showed that elderly individuals had shorter TUG performance time and increased gait speeds after horse riding exercise ${ }^{9,17)}$. In our present study, the HRS group demonstrated better dynamic balance ability and gait ability than those of the ball exercise group. It was possible for the participants to predict their own actions in the exercises on the ball, when riding on the HRS, which generates three-dimensional dynamic movements (forward and backward, left and right, and up and down), the movements couldn't be predicted and greater, postural responses were elicited by the HRS. The movement of horse riding provides inputs to the motor, visual, somatosensory and vestibular systems. Horse riding is believed to promote motor performance and strengthen the lower limb muscles ${ }^{12}$. Heinereported that the movement of a horse generates continuous vestibular inputs. Stimulating postural reaction, and feedback and feedforward repeatedly take place during horse riding exercise to maintain a sitting position and to execute efficient postural strategies ${ }^{23}$.

Although the horse riding exercise was performed in different forms, the exercises were verified to have positive effects on the balance and functional mobility of the elderly.Many elderly people commonly experience late-life depression ${ }^{24}$. Kim and Jungreported that leisure activity programsimproved physiological, psychological functions and daily living activities of the elderly living in a city ${ }^{4}$. Horse riding exercise not only elicits physical improvement, but also provides psychological pleasure and physical convenience. In the indoor HRS exercise that was conducted in this study, the elderly subjects were able to experience horse riding while looking at an image depicting a virtual reality; therefore, they were able to enjoyably participate. Simulated horse riding exercise on a ball may also be performed by elderly people at anytime without restriction of time or space, and has the merit that it may be performed by a group of people in hospitals or institutions. The limitations of this study were as follows. The number of subjects was small and was not representative of all elderly people. Also, follow-up evaluations of how long the improved balance and gait function of elderly patients staying in hospitals are maintained are necessary.

In an aging society, the number of ole people is continuously increasing, and the need of methods to prevent elderly people's falls and enhance their balance ability has been made clear. Indoor horse riding exercise is a good method for improving elderly people's balance ability and preventing falls.

\section{ACKNOWLEDGEMENT}

This work was supported by the Daegu University Research Grant, Grant No 20120330.

\section{REFERENCES}

1) Sihvonen S, Kulmala J, Kallinen M, et al.: Postural balance and self-reported balance confidence in older adults with a hip fracture history. Gerontology, 2009, 55: 630-636. [Medline] [CrossRef]

2) Crotty M, Unroe K, Cameron ID, et al.: Rehabilitation interventions for improving physical and psychosocial functioning after hip fracture in older people. Cochrane Database Syst Rev, 2010, CD007624. [Medline]

3) McClure R, Turner C, Peel N, et al.: Population-based interventions for the prevention of fall-related injuries in older people. Cochrane Database Syst Rev, 2005, CD004441. [Medline] 
4) Kim YS, Jung HM: Effects of the leisure activity program on physical, physiological, psychological functions and activities of daily living in Elderly. J Korean Data Anal Soc, 2006, 8: 971-987.

5) Möhler R, Richter T, Köpke S, et al.: Interventions for preventing and reducing the use of physical restraints in long-term geriatric care. Cochrane Database Syst Rev, 2011, CD007546. [Medline]

6) Dykes PC, Carroll DL, Hurley A, et al.: Fall prevention in acute care hospitals. JAMA, 2010, 304: 1912-1918. [Medline] [CrossRef]

7) Cameron ID, Murray GR, Gillespie LD, et al.: Interventions for preventing falls in older people in nursing care facilities and hospitals. Cochrane Database Syst Rev, 2010, CD005465. [Medline]

8) Cumming RG, Sherrington C, Lord SR, et al.: Cluster randomised trial of a targeted multifactorial intervention to prevent falls among older people in hospital. BMJ, 2008, 336: 758-760. [Medline] [CrossRef]

9) Araujo TB, Silva NA, Costa JN, et al.: Effect of equine-assisted therapy on the postural balance of the elderly. Rev Bras Fisioter, 2011, 15: 414-419. [Medline] [CrossRef]

10) Beinotti F, Correia N, Christofoletti G, et al.: Use of hippotherapy in gait training for hemiparetic post-stroke. Arq Neuropsiquiatr, 2010, 68: 908 913. [Medline] [CrossRef]

11) Debuse D, Chandler C, Gibb C: An exploration of German and British physiotherapists' views on the effects of hippotherapy and their measurement. Physiother Theory Pract, 2005, 21: 219-242. [Medline] [CrossRef]

12) Giagazoglou P, Arabatzi F, Dipla K, et al.: Effect of a hippotherapy intervention program on static balance and strength in adolescents with intellectual disabilities. Res Dev Disabil, 2012, 33: 2265-2270. [Medline] [CrossRef]

13) Zadnikar M, Kastrin A: Effects of hippotherapy and therapeutic horseback riding on postural control or balance in children with cerebral palsy: a meta-analysis. Dev Med Child Neurol, 2011, 53: 684-691. [Medline] [CrossRef]

14) Bronson C, Brewerton $K$, Ong J, et al.: Does hippotherapy improve balance in persons with multiple sclerosis: a systematic review. European Journal of Physical and Rehabilitation Medicine, 2010, 46: 347. [Medline]

15) Lechner HE, Kakebeeke TH, Hegemann D, et al.: The effect of hippotherapy on spasticity and on mental well-being of persons with spinal cord injury. Arch Phys Med Rehabil, 2007, 88: 1241-1248. [Medline] [CrossRef]

16) Carrillo EH, Varnagy D, Bragg SM, et al.: Traumatic injuries associated with horseback riding. Scandinavian journal of surgery. SJS: official Organ for the Finnish Surgical Society and the Scandinavian Surgical Society, 2007, 96: 79

17) Mitani Y, Doi K, Yano T, et al.: Effect of exercise using a horse-riding simulator on physical ability of frail seniors. J Phys Ther Sci, 2008, 20: 177-183. [CrossRef]

18) Shurtleff TL, Standeven JW, Engsberg JR: Changes in dynamic trunk/ head stability and functional reach after hippotherapy. Arch Phys Med Rehabil, 2009, 90: 1185-1195. [Medline] [CrossRef]

19) Steffen TM, Hacker TA, Mollinger L: Age-and gender-related test performance in community-dwelling elderly people: six-minute walk test, Berg Balance Scale, Timed Up \& Go Test, and gait speeds. Phys Ther, 2002, 82: 128-137. [Medline]

20) Bohannon RW: Comfortable and maximum walking speed of adults aged 20-79 years: reference values and determinants. Age Ageing, 1997, 26: 15-19. [Medline] [CrossRef]

21) Melzer I, Kurz I, Oddsson LI: A retrospective analysis of balance control parameters in elderly fallers and non-fallers. Clin Biomech (Bristol, Avon), 2010, 25: 984-988. [Medline] [CrossRef]

22) Kim YH: A study on the related of daily life activity and the health related quality of life between the elderly at home and at institution. J Korean Data Anal Soc, 2009, 11: 1273-1287.

23) Heine B: Hippotherapy. A multisystem approach to the treatment of neuromuscular disorders. Aust J Physiother, 1997, 43: 145. [Medline]

24) Nam JS, Yang JH: Factors influencing depression of frail elderly with chronic disease in long-term care hospitals. J Korean Data Anal Soc, 2012, 14: 3035-3047. 